\title{
Use of Rain Classroom as a Teaching Tool in a Biochemistry Course
}

\author{
Bo Shu ${ }^{1, *}$, Fang Fan $^{1} \&$ Xinting $\mathrm{Zhu}^{1}$ \\ ${ }^{1}$ Department of Biochemistry, School of Basic Medicine, Zunyi Medical University, Zunyi, Guizhou, China \\ *Correspondence: Department of Biochemistry, School of Basic Medicine, Zunyi Medical University, 6\# Xuefuxi \\ Road, Xinpu new District, Zunyi City, Guizhou Province, China. E-mail: shubo1014@126.com
}

Received: June 13, 2019

Accepted: July 10, 2019 Online Published: July 22, 2019

doi:10.5430/jct.v8n3p15

URL: https://doi.org/10.5430/jct.v8n3p15

\begin{abstract}
In order to stimulate learning interest among university students towards biochemistry and to improve learning outcomes, we performed a 10-week biochemistry Rain Classroom teaching experiment among students majoring in clinical medicine. Rain Classroom is a plug-in for WeChat, a smartphone instant messaging application. Teachers can post teaching resources on the Rain Classroom platform, administer tests, and communicate with students. Rain Classroom can also be used to automatically collect course learning data from students. When teaching is complete, questionnaire surveys can be conducted, and test scores can be outputted. Results showed that students were interested in the biochemistry Rain Classroom teaching application, and that the application increased their enthusiasm for the course materials. There were significant improvements in the learning outcomes in students given Rain Classroom teaching, compared to those given traditional PowerPoint slideshow lessons. We conclude that the Rain Classroom tool is a new mobile learning application that promotes self-learning and improves learning outcomes in biochemistry learning.
\end{abstract}

Keywords: rain classroom, biochemistry teaching, active learning

\section{Introduction}

With the development of information technology and the integration of communication networks, the use of mobile digital media which consists mainly of smartphones and tablets has permeated various aspects of learning (Curran et al., 2019). Mobile learning is meant to assist students in learning by use of mobile devices, such as smartphones, and it has been developed under a new social development model. Due to the advantages of portability and the ability to access information at any time, mobile learning tools are being used for high school teaching (Wang et al., 2017). WeChat is a free instant messaging application that was launched in 2011 by Tencent Holdings Limited and covers more than $94 \%$ of smartphone users in China. Currently, WeChat is the most popular social media application (Tu, Yan, Jie, Ying, \& Huang, 2018). Rain Classroom is a new smart teaching tool that is combined with WeChat. Rain Classroom integrates its complex information technology methods in PowerPoint slideshow and WeChat. Pre-class learning, classroom teaching, and post-class revision can all be integrated into the Rain Classroom teaching system when teachers use PowerPoint slideshow for teaching and students use WeChat. This optimizes the conventional model of teaching and learning and drives education reform. Biochemistry is an essential course for students planning careers in the life sciences. Since the course content is continuously increasing in quantity and complexity, it becomes more difficult for students to understand and memorize the content. Therefore, the WeChat platform, which is widely used by students, can be combined with the Rain Classroom tool to extend traditional teaching outside the classroom, thereby promoting learning proactivity and enthusiasm in students, as well as improve learning outcomes (Tang et al., 2018). The aim of this paper is to describe the practical methods of this approach and share experiences of using Rain Classroom to teach biochemistry to students majoring in clinical subjects.

\section{Rain Classroom Teaching Characteristics and Functions}

In recent years, with the widespread popularity of smartphones, many new forms of social media have experienced a boom in development. Blog, WeChat, and other instant messaging platforms have become the main mode of communication and interaction between students. Based on the 2018 WeChat Annual Data Report, the number of 
monthly active WeChat users reached 1.082 billion in 2018. More than $99 \%$ of university students in China use WeChat. Under the background of clear access to information in real time and the diversity of information, traditional classroom teaching models cannot meet students' intense demands of learning. E-learning is easier on mobile phones than on computers. The use of smartphones for mobile learning was developed due to its flexibility and convenience (Klimova, 2018). Free smart learning platforms in various mobile environments were successively developed, such as Google Classroom (Dash, 2019). Better access to learning material and supplementary teaching resources, helpfulness of immediate feedback, and learning outside of class environment were reported by students. Rain Classroom is a new free-to-use smart teaching tool that was developed by Tsinghua University on the WeChat platform in 2016.

The major characteristics of Rain Classroom are as follows: 1) Easy to use. Rain Classroom is a small program installed in WeChat as a plugin and only a smartphone is required to access a Rain Classroom account. Scanning the QR code for Rain Classroom allows users to enter the classroom, with no need to download any additional application or acquire additional hardware. 2) Self-learning at anytime and anywhere. After every class, the teacher will add relevant content to Rain Classroom. Students just need to access Internet through their smartphones to get courseware learning and practice assignments. 3) Real-time teacher-student interactions. Rain Classroom uses information technology methods to link PowerPoint with WeChat. Relations among classroom teaching, online teaching, and students' self-learning are established through mobile phones to achieve long-term efficiency in teaching. Multi-faceted teaching interactions are fostered between teachers and students. 4) Digitization of teaching outcomes. In conventional teaching, teaching outcomes are usually ascertained through end-of-term tests and teachers are unable to determine a students' status in real time. This can also cause some students not to study at ordinary times, but to study hard before the final exam. Rain Classroom, however, collects, records, and analyzes various data during learning and digitizes previously invisible learning outcomes so that the assessment of teaching outcomes also enters the digital age.

Rain Classroom has two major functions: resource generation and functionalization. Resource generation includes teacher's courseware, exercises, literature, relevant news reports, and links to new websites, as well as MOOC-linked instructional videos. Functionalization mainly includes the calculation of student attendance, statistical analysis of classroom practice, course discussion, bullet-screen comments, the release of courseware, analysis of results and other interactive methods. These functions of the Rain Classroom can be performed before class, during class, and after class; therefore, students can share resources at any time or place. One example is the "do not understand" button in Rain Classroom, which enables students to give feedback on learning difficulties on the platform. The learning data of students on Rain Classroom is automatically collected and analyzed, and teachers can assess teaching outcomes in a timely manner. As a result of this function, trustworthy interactions between teachers and students are formed. The functions of Rain Classroom teaching are summarized in Figure 1.

\section{Pre-learning before class}

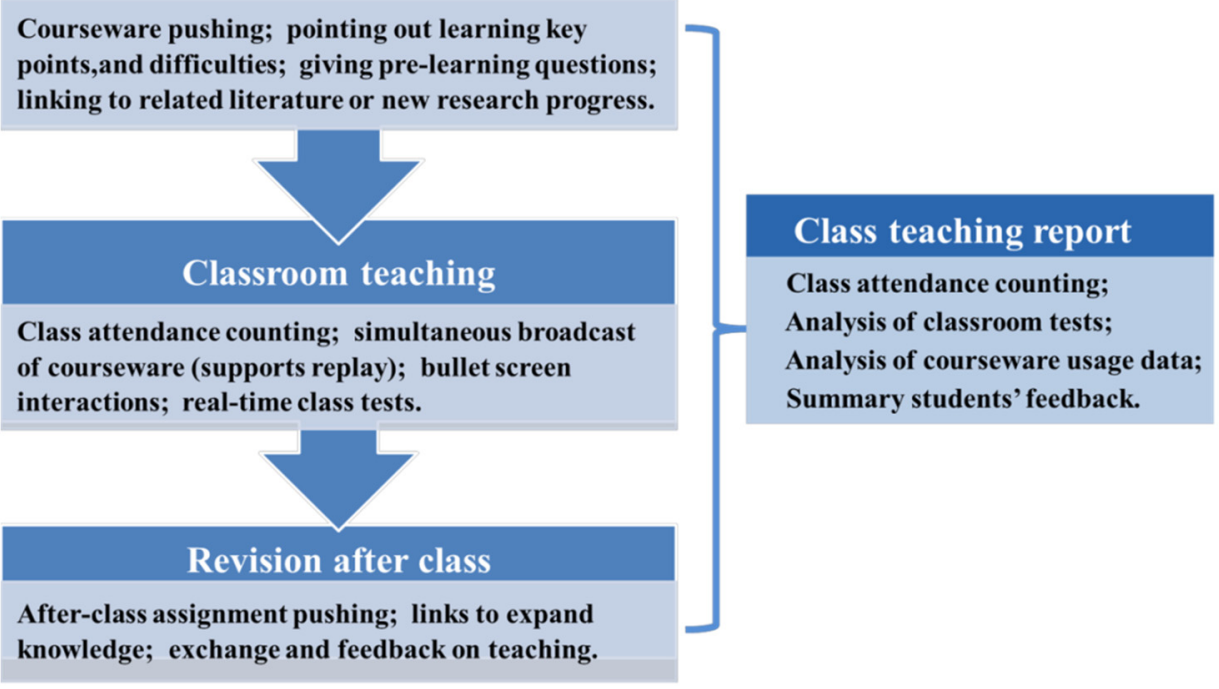

Figure 1. Functions of Rain Classroom Teaching 


\section{Advantages of Using Rain Classroom in Biochemistry Teaching}

Biochemistry is a discipline in which the principles and methods of chemistry are used to study biological phenomena at the molecular level. It is an essential foundational module for undergraduates in medical university. The course content of this subject mainly includes four major areas which include various knowledge points, such as chemical composition and structure, substance metabolism and regulation, and transfer and regulation of genetic information. In traditional models, teaching occurs mainly through lectures. Furthermore, the course content is rigid, teaching methods are identical, and students acquire knowledge passively. Students' proactivity toward learning and enthusiasm also tend to be poor. For example, substances metabolism involve the synthesis and degradation of substances. Each chemical step involves changes in the molecular structure, transfer of functional groups, and energy calculations of substrates, all of which occur in different organelles. This topic is abnormally abstract and covers a dynamic and continuously changing process. The teacher's 40-minute lecture is too short for students to digest and absorb knowledge effectively. Theoretical courses for biochemistry are mostly large lectures. Lecture halls are often filled with approximately 200 students. This type of classroom is often very quiet, and teachers try their best to explain the material as students take notes without disturbing each other. The teacher will occasionally ask some extremely simple questions and the students will answer yes or no. The teacher will then use his/her experience to judge the students' mastery of the knowledge points, and teacher-student interactions are usually ineffective. These problems cannot be solved using traditional PowerPoint slideshow teaching methods alone.

The use of Rain Classroom teaching can enable students to move themselves inside the teaching process and actively learn under the organization and management of teachers. Before class, students carry out brief pre-learning through the courseware, pre-learning questions, and other resources provided by the teachers to ensure they gain initial awareness of the course content and can brainstorm the questions they want to ask. During class, students focus on listening to the class and not on taking notes. When they find some deficit in or have questions regarding the course content, they can replay the PowerPoint slideshow content on their mobile phones. The bottom of each PowerPoint slide contains a feedback button to label the slide as not well explained so that teachers receive feedback after class. Teachers can add small tests during the PowerPoint slideshow Rain Classroom courses at any time and set time limits for answering questions. Based on the answers provided, teachers will be able to assess understanding of the difficult material by the students and adjust the course content and time allocation in a timely manner. Students can also interact with teachers through Rain Classroom and can propose their own ideas for others to discuss. This can cultivate independent thinking, stimulate courage to criticize and question, as well as promote innovation. The teacher can also provide relevant videos or web links on Rain Classroom to stimulate the learning interest of students. After the class, students will complete the assignments that were placed in Rain Classroom by the teachers to expand their reading skills. In addition, teachers can push the PowerPoint slide recordings for each slide on the platform through their mobile phones to promote learning outside of the classroom, and students are able to carry out learning exchanges and feedback with teachers or other students at any time and any place. The application of Rain Classroom overcomes temporal and spatial limitations in traditional PowerPoint slideshow teaching models.

\section{Design and Implementation of Rain Classroom in the Teaching of Biochemistry}

In order to assess the teaching results of the mobile learning tool Rain Classroom in biochemistry instruction, we carried out a 10-week Rain Classroom teaching program for Class 2017 students majoring in clinical subjects. Within a single cohort of undergraduates majoring in clinical subjects, a total of 172 students were given PowerPoint slideshow conventional teaching. These students served as the control class. Another 171 students received Rain Classroom teaching and are referred to as the experimental class. Before the experiment began, these 171 students downloaded the WeChat application so they could use the Rain Classroom tool. These two classes had similar mean scores in various previous courses and all met the basic conditions for the experiment. The course period was from September 2018 to November 2018 and consisted of 10 weeks of teaching. Using section 3 of chapter 16 in the course material, hepatic biotransformation, as an example, the Rain Classroom course was designed as follows:

\subsection{Before Class}

Students entered Rain Classroom using their mobile phones and viewed the resources that the teacher had sent in advance (Figure 2). These resources were used for pre-learning. Students can click on the push title to see the specific content. Publication of the teaching courseware, webpage links and news were used to stimulate the students' thinking: Is it true that alcohol should not be consumed after antibiotics? How does this relate to the content of this class? Pushed prepare question: What is biotransformation? Why is in vivo biotransformation required? What is the mechanism of biotransformation? Pre-learning key points: Definition and process of biotransformation. Difficulties: 
Definition of biotransformation.

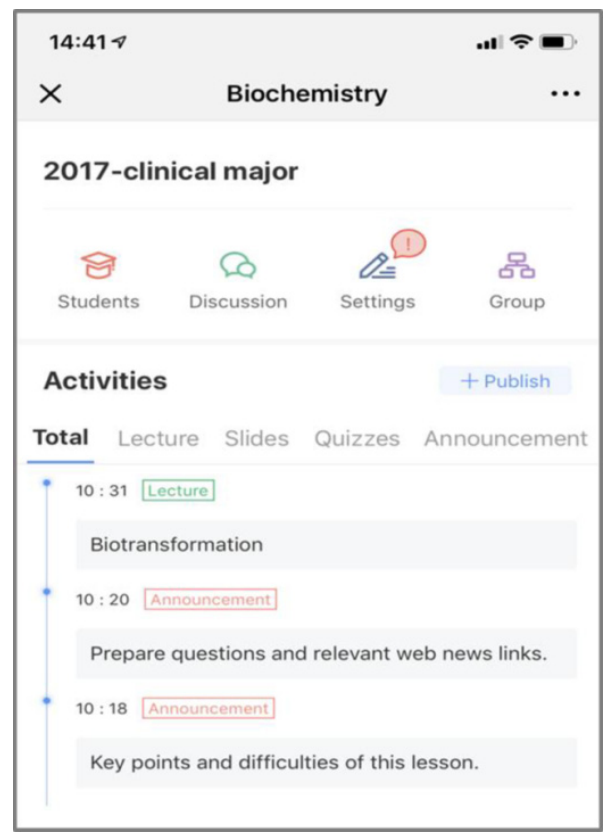

Figure 2. Pushing Learning Resources in Smartphone with Rain Classroom

\subsection{During Class}

Teachers conducted lectures by entering Rain Classroom from the PowerPoint slideshow into their computers and entering and generating a QR code for connecting to the classroom. Students used WeChat on their mobile phones to scan this code to enter the Rain Classroom, and Rain Classroom automatically collected students' names (Figure 3). During the class, Rain Classroom was connected to the PowerPoint slides information from the teacher in real time. Students were able to leave comments on all slides related to content they did not understand (Figure 4). Students could also engage in discussion or replay any slide on their mobile phones. The teacher inserted relevant massive open online courses or Internet videos in Rain Classroom for broadcast, prepared quizzes for use in class, and set a time limit for answering questions. Students answered questions on their mobile phones. After the test was over, the computer immediately showed the answer status.

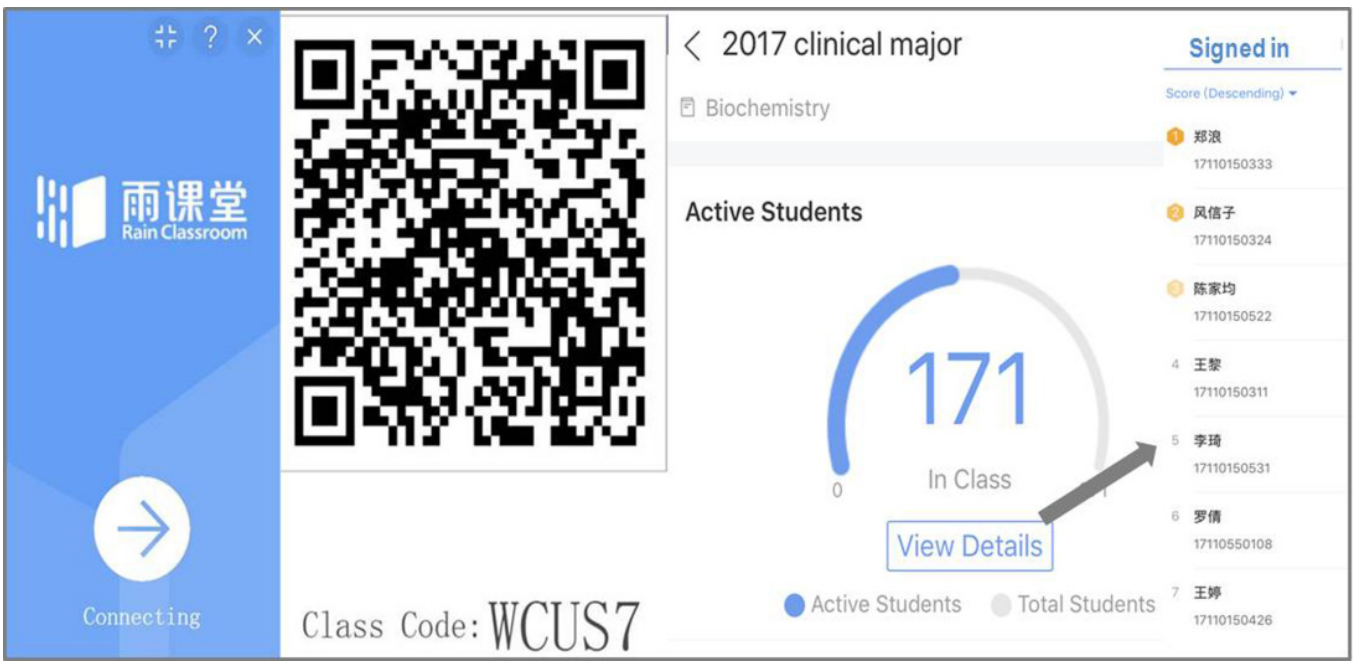

Figure 3. Schematic Diagram of Rain Classroom QR Code and Students Signed in Data 


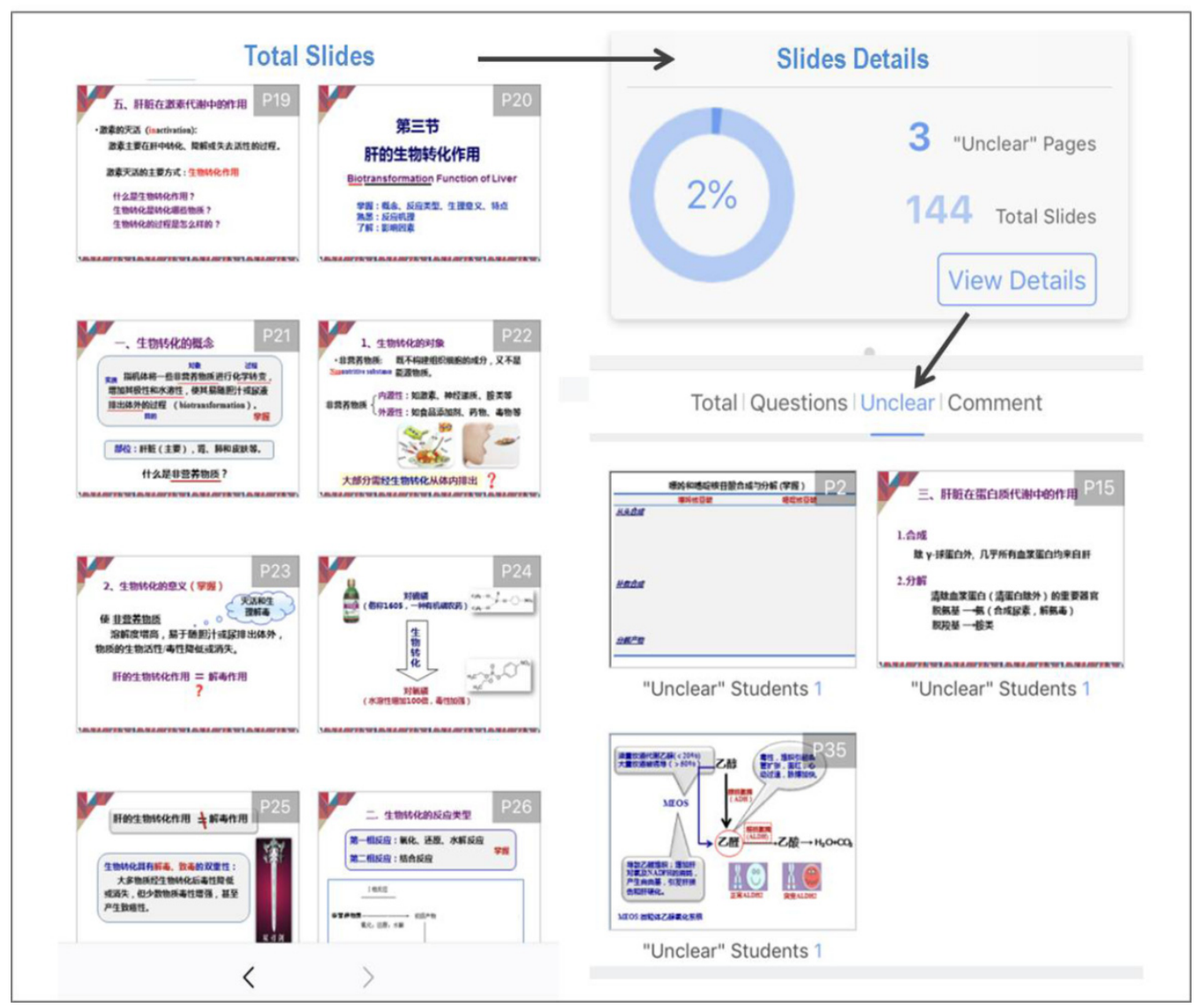

Figure 4. Simultaneous Plays of PowerPoint Slideshow Courseware in Rain Classroom and Displays the Unclear Courseware

\subsection{After the Class}

Assignments were given out on Rain Classroom and reading materials were provided. The teacher may carry on the small test at any time in the Rain Classroom and the test results were automatic analyzed (Figure 5). The teacher was able to reflect on the teaching process through data that were automatically collected and analyzed by Rain Classroom. During data analysis, brilliant students with a good grasp of the class content as well as students with a poor understanding of the content were easy to identify. Therefore, teachers can pay more attention to the underperforming students (Figure 6). Overall, students could examine and learn the content of the course using Rain Classroom on their mobile phones, as well as provide feedback and interact with teachers and other students in the forum. 


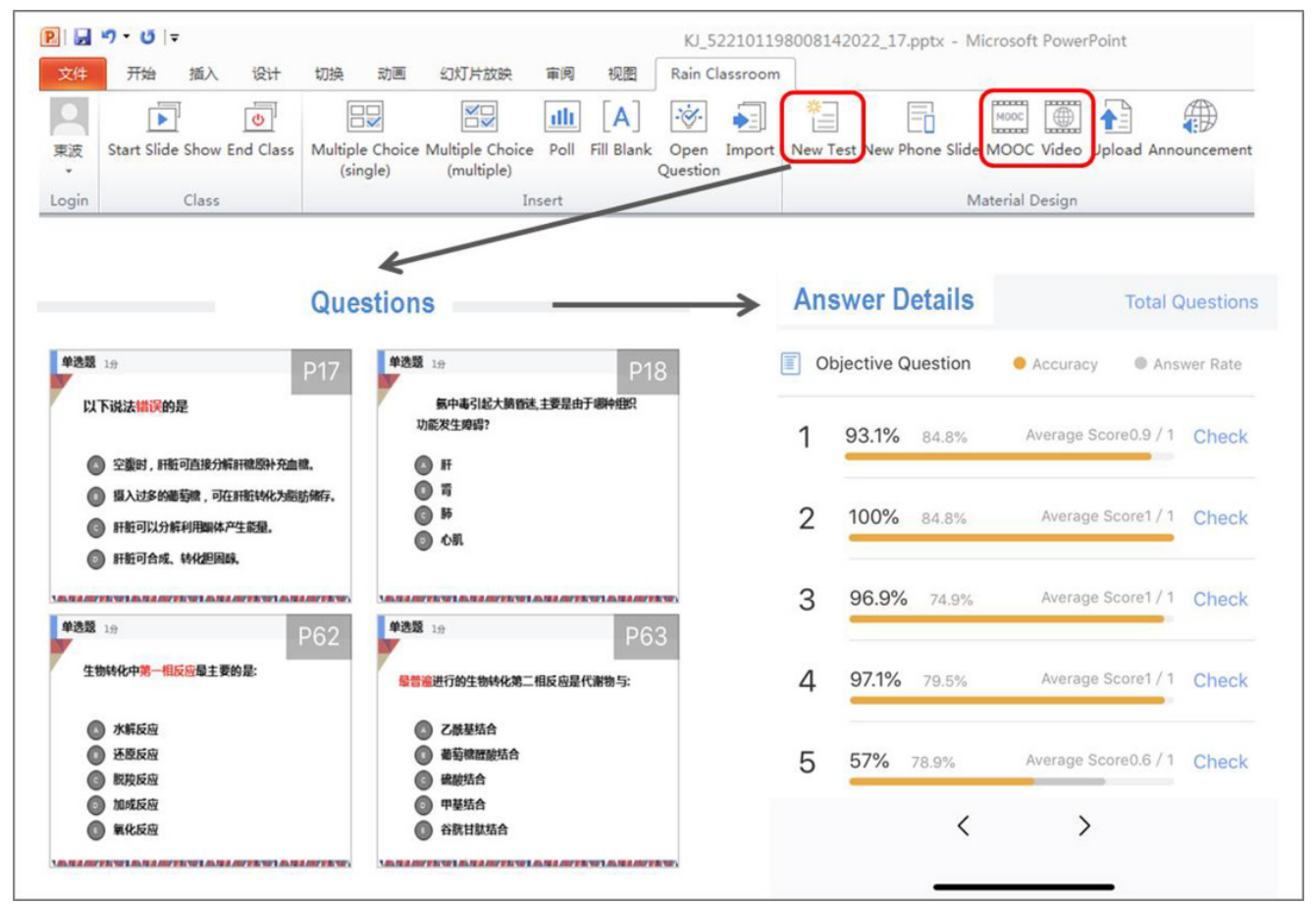

Figure 5. Rain Classroom Plug-in Interface and Student Classroom Test Analysis Results

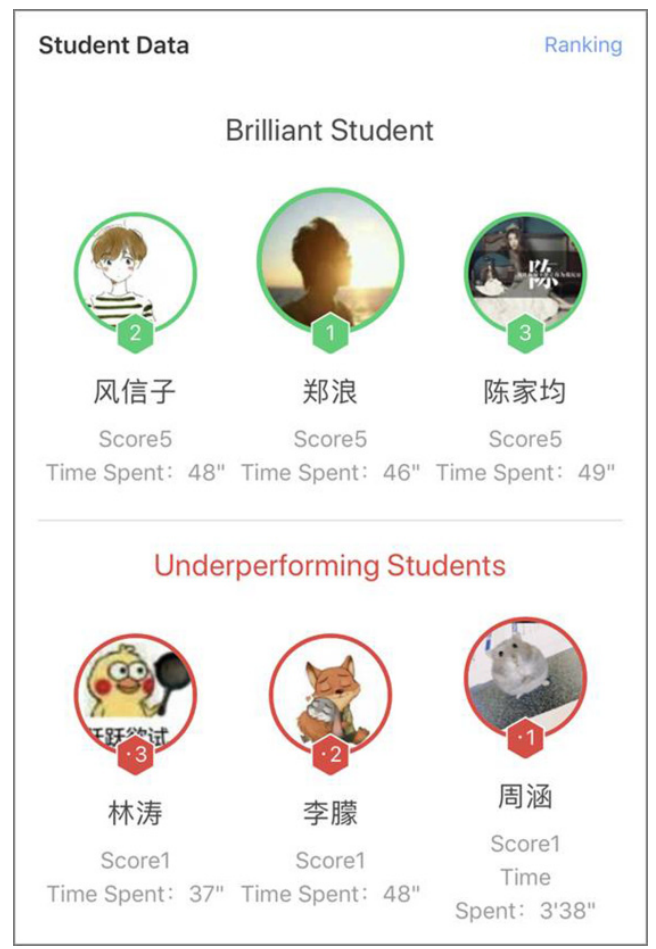

Figure 6. Analysis of Students' Learning Performance in the Rain Classroom

\section{Assessment of Rain Classroom in the Teaching of Biochemistry}

Ten weeks into the course, we administered a questionnaire survey on 171 students who received Rain Classroom teaching. A total of 171 copies of the 2017 clinical undergraduate biochemistry Rain Classroom teaching outcome questionnaires were distributed and 171 valid questionnaires were collected. The recovery rate was $100 \%$. This questionnaire was used to examine the attitudes and operations of students towards biochemistry Rain Classroom 
teaching. Students found that Rain Classroom was easy to use and they could access teaching resources at any time via their mobile phones. In addition, they were able to conduct effective exchange with teachers and understand their ranking with respect to the overall learning results in the class through Rain Classroom. This allowed students to objectively evaluate their learning outcomes. Overall, Rain Classroom teaching showed significant advantages over traditional teaching. However, students mentioned some shortcomings of Rain Classroom. For example, Rain Classroom has specific Internet requirements and leads to over-reliance on mobile phones for learning.

Table 1. Investigation on the Effects of Rain Classroom Teaching $(\mathrm{n}=171)$

\begin{tabular}{|c|c|}
\hline Survey questions & Proportions of students \\
\hline Is Rain Classroom easy to use in learning? & Yes: $92.4 \%$, No: $7.6 \%$, Not sure: 0 \\
\hline $\begin{array}{l}\text { Is Rain Classroom teaching helpful to you in learning } \\
\text { the course? }\end{array}$ & Yes: $86.0 \%$, No: $7.6 \%$, Not sure: $6.4 \%$. \\
\hline Did you use Rain Classroom before and after classes? & Yes: $89.5 \%$, No: $10.5 \%$, Not sure: 0 . \\
\hline $\begin{array}{l}\text { Which functions in Rain Classroom teaching do you } \\
\text { find to be the most useful? (Can select more than } 1 \\
\text { option) }\end{array}$ & $\begin{array}{l}\text { Pushing of teaching resources: } 84.3 \% \text {, Links to video webpages: } \\
59.3 \% \text {, Simultaneous classroom slides: } 67.4 \% \text {, Classroom tests: } \\
52.9 \% \text {, Feedback on difficulties: } 74.4 \% \text {, Teacher-student } \\
\text { interactions: } 82.6 \% \text {, Others: } 8.7 \% \text {. }\end{array}$ \\
\hline $\begin{array}{l}\text { Would you prefer Rain Classroom teaching or } \\
\text { traditional PowerPoint slideshow teaching? }\end{array}$ & $\begin{array}{l}\text { Rain Classroom teaching: } 87.2 \% \text {, Traditional teaching: } 8.1 \% \text {, Not } \\
\text { sure: } 4.7 \% \text {. }\end{array}$ \\
\hline \multicolumn{2}{|l|}{$\begin{array}{l}\text { Classroom teaching in other foundational professional } \\
\text { subjects? }\end{array}$} \\
\hline \multicolumn{2}{|l|}{ Any comments or suggestions to this teaching method: } \\
\hline $\begin{array}{l}\text { Long-term reliance on mobile phones and other mobil } \\
\text { are sometimes affected by Internet speed. It is hopeful } \\
\text { in the Rain Classroom. }\end{array}$ & $\begin{array}{l}\text { vices for learning will harm vision. Classroom learning and tests } \\
\text { t teachers can push more subject progress and learning resources }\end{array}$ \\
\hline
\end{tabular}

Table 1 showed typical questions and answers. In general, the results showed that the students were satisfied with the Rain Classroom teaching.

To further study the teaching effects of Rain Classroom for biochemistry teaching, we carried out a small test for the content learned in 10 weeks in a Rain Classroom class versus a traditional PowerPoint slideshow teaching only class and performed statistical analysis on the results. Independent sample t-tests were used for a comparison of the effectiveness of teaching in the two groups.

Table 2. Scoring Rates in Different Teaching Models (mean \pm SD, \%)

\begin{tabular}{llcc}
\hline Teaching models & N & Scoring rates (mean \pm SD, \%) & Sig. (2-tailed) \\
\hline PowerPoint slideshow teaching only & 172 & $70.03 \pm 12.12$ & 0.0012 \\
Rain Classroom teaching & 171 & $74.14 \pm 12.63$ & \\
\hline
\end{tabular}

Table 2 showed that Sig. (2-tail) $=0.0012<0.05$ and that there is a significant difference in the mean. The mean value for traditional PowerPoint slideshow teaching (mean result), which is $70.03 \pm 12.12$, is significantly lower than the mean value for Rain Classroom teaching (mean result), which is $74.14 \pm 12.63$. The results suggested that using Rain Classroom can effectively improve the test scores of students.

\section{Summary}

With the continuous development of science and technology, combined teaching methods that use Internet technology, mobile networks, and education, such as "Internet + education" and "mobile education" have continued to emerge (Kadivar, Seyedfatemi, Mokhlesabadi Farahani, Mehran, \& Pridham, 2017). These new education models mainly rely on mature wireless mobile networks, the World Wide Web, and multimedia technologies to allow 
students and teachers to use computers and mobile devices, such as mobile phones, to perform interactive teaching activities. Digitization is becoming increasingly important as an integral part of medical school curricula (Kuhn, Frankenhauser, \& Tolks, 2018). Rain Classroom is an example of a new teaching model that is produced in this informatization system. In this study, we arranged 10 weeks of Rain Classroom teaching for 171 students for the teaching of biochemistry theory. In addition, questionnaire surveys and corresponding analysis were conducted to analyze and assess the results of Rain Classroom in practice. Results showed that this new teaching method can stimulate learning interest in students, cultivate self-learning capabilities, expand student knowledge, and improve learning results and outcomes. Furthermore, the teachers provided feedback based on their experiences using Rain Classroom for teaching biochemistry; this feedback is detailed below.

First, Rain Classroom is a place to store classroom knowledge and also serves as a tool for the transmission and application of knowledge. Educational resources provided in Rain Classroom facilitates discussion between teachers and students during learning, allowed for the exchange of textbook knowledge, and provided links to the latest developments in the subject. This guided students to criticize and question existing knowledge and cultivate independent thinking and innovative ideas. This teaching model applied new smart teaching tools in a new era and background. Teachers therefore must embrace these new concepts. Based on this study, teachers should use new media and tools to develop modern teaching techniques and continuously upgrade their educational and teaching prowess. Teachers should assess what their students wish to learn and what they will learn as key points and targets for teaching and improve their adaptability to new teaching models. Universities train individuals with multiple talents. Therefore, in addition to teaching foundational professional knowledge and skills, universities should also teach students self-learning methods and the ability to question and innovate (Cubas Rolim et al., 2017). Rain Classroom may take the community one step closer to achieving this goal.

Second, during the use of Rain Classroom, teachers had a profound experience involving the use of big data. The Rain Classroom big data service provides extremely useful data support for the course assessment system. Traditional course assessment systems focus on final assessments and are often conducted at the end of a semester, in which one examination determines the student's professional results. The teacher commonly uses this result to assess the student's learning outcomes in that semester, which is similar to that the results of the National College Entrance Examination will determine one's life in China. This process has shortcomings; therefore, most universities advocate new class assessment systems to adapt to a reformed and practical teaching model. This is a form of diagnostic assessment and formative assessment (Lea Bonner et al., 2018). Through the blended teaching method, teachers can build an efficient and efficient classroom teaching management system (Peacock \& Grande, 2016). The use of Rain Classroom provides a service for these integrated assessments enabling teachers to shift from experience-driven teaching to data-driven teaching models. In traditional classrooms, it is impossible to track student learning in real time. However, this is possible using Rain Classroom. Through attendance statistics, summaries of pre-learning status, analysis of test results, assignment completion statistics, and a names list of strong and weak students, teachers can conduct qualitative and quantitative assessments of the learning preparedness and acceptance of students. Data analysis in Rain Classroom changed the final assessment method in which the end of term examination results were used to evaluate learning outcomes and improved the indicator system and assessment criteria in formative assessment. Teachers are now able to understand the students' learning progress at any time and obtain continuous feedback for teaching. This provides references for adjustment to teaching plans at any time as well as improvements to teaching methods for teachers. This assessment system can ultimately encourage students to carry out extracurricular self-learning, and rationally arrange their learning time and process.

In today's world, in which traditional education has become increasingly unsuited, reforms to educational models are essential for high school teachers. The purpose of reform is to innovate and update education concepts and employ new teaching methods to completely redesign teaching models. Advanced network technologies, multimedia technologies, information technology, and the mobile Internet have allowed the community to establish new teaching models. As a mobile educational tool plugin in the WeChat application in mobile phones, Rain Classroom simultaneously considers the three aspects of students, teachers, and educational resources, and organically integrates these aspects through its platform. Rain Classroom has improved many deficiencies, including teacher-based classroom teaching in traditional teaching, limited teaching resources, few teacher-student interactions, and implementation of final evaluations, and it has many prospects for practical applications.

\section{Acknowledgments}

This work was funded by the Education and teaching reform project of Zunyi Medical University (xjjg2015-02-9), 
Education and teaching reform project of basic medicine school of Zunyi Medical University (jcyx201820), Education and teaching reform fund of basic medicine department of Medicine \& Technology School of Zunyi Medical University (jcb201501)

\section{Conflicts of Interest}

The authors declare that they have no competing interests.

\section{References}

Cubas Rolim, E., Martins de Oliveira, J., Dalvi, L. T., Moreira, D. C., Garcia Caldas, N., Fernandes Lobo, F., \& Hermes-Lima, M. (2017). Blog construction as an effective tool in biochemistry active learning. Biochem Mol Biol Educ., 45(3), 205-215. https://doi.org/10.1002/bmb.21028

Curran, V., Fleet, L., Simmons, K., Lannon, H., Gustafson, D. L., Wang, C., \& Wetsch, L. (2019). Adoption and Use of Mobile Learning in Continuing Professional Development by Health and Human Services Professionals. $J$ Contin Educ Health Prof., 39(2), 76-85. https://doi.org/10.1097/ceh.0000000000000243

Dash, S. (2019). Google classroom as a learning management system to teach biochemistry in a medical school. Biochem Mol Biol Educ., 47(4), 404-407. https://doi.org/10.1002/bmb.21246

Kadivar, M., Seyedfatemi, N., Mokhlesabadi Farahani, T., Mehran, A., \& Pridham, K. F. (2017). Effectiveness of an internet-based education on maternal satisfaction in NICUs. Patient Educ Couns., 100(5), 943-949. https://doi.org/10.1016/j.pec.2016.11.005

Klimova, B. (2018). Mobile Learning in Medical Education. $J$ Med Syst., 42(10), 194. https://doi.org/10.1007/s10916-018-1056-9

Kuhn, S., Frankenhauser, S., \& Tolks, D. (2018). Digital learning and teaching in medical education : Already there or still at the beginning?. Bundesgesundheitsblatt Gesundheitsforschung Gesundheitsschutz, 61(2), 201-209. https://doi.org/10.1007/s00103-017-2673-z

Lea Bonner, C., Staton, A. G., Naro, P. B., McCullough, E., Lynn Stevenson, T., Williamson, M., \& Momary, K. M. (2018). A compliance assessment of midpoint formative assessments completed by APPE preceptors. Curr Pharm Teach Learn., 10(1), 14-20. https://doi.org/10.1016/j.cptl.2017.09.010

Peacock, J. G., \& Grande, J. P. (2016). An online app platform enhances collaborative medical student group learning and classroom management. Med Teach., 38(2), 174-180. https://doi.org/10.3109/0142159x.2015.1020290

Tang, W. N., Zhang, H. W., Tan, X., Yin, J. H., Ding, Y. B., \& Cao, G. W. (2018). [Research on reform of epidemiology teaching]. Zhonghua Liu Xing Bing Xue Za Zhi, 39(7), 1009-1012. https://doi.org/10.3760/cma.j.issn.0254-6450.2018.07.027

Tu, S., Yan, X., Jie, K., Ying, M., \& Huang, C. (2018). WeChat: An applicable and flexible social app software for mobile teaching. Biochem Mol Biol Educ., 46(5), 555-560. https://doi.org/10.1002/bmb.21170

Wang, J., Gao, F., Li, J., Zhang, J., Li, S., Xu, G. T., Lu, L. (2017). The usability of WeChat as a mobile and interactive medium in student-centered medical teaching. Biochem Mol Biol Educ., 45(5), 421-425. https://doi.org/10.1002/bmb.21065 